\title{
Effects on Lignin Redistribution in Eucalyptus globulus Fibres Pre-Treated by Steam Explosion: A Microscale Study to Cellulose Accessibility
}

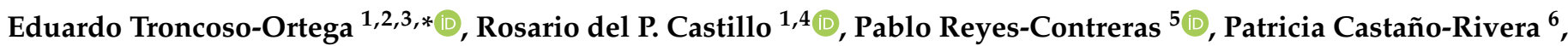 \\ Regis Teixeira Mendonça ${ }^{1,7}$, Nicolás Schiappacasse ${ }^{8}\left(\mathbb{D}\right.$ and Carolina Parra ${ }^{1,2}$ (i) \\ 1 Laboratorio de Recursos Renovables, Centro de Biotecnología, Barrio Universitario s/n, \\ Universidad de Concepción, Concepción 4030000, Chile; rosariocastillo@udec.cl (R.d.P.C.); \\ rteixeira@udec.cl (R.T.M.); roparra@udec.cl (C.P.) \\ 2 ANID-Millennium Science Initiative Program-Millennium Nuclei on Catalytic Process towards \\ Sustainable Chemistry (CSC), Av. Vicuña Mackenna 4860, Macul, Santiago 8320000, Chile \\ 3 Facultad de Ciencias Químicas, Barrio Universitario s/n, Universidad de Concepción, \\ Concepción 4030000, Chile \\ 4 Facultad de Farmacia, Barrio Universitario s/n, Universidad de Concepción, Concepción 4030000, Chile \\ 5 Centro de Excelencia en Nanotecnología (CEN), Leitat Chile, Santiago 8320000, Chile; preyes@leitat.cl \\ 6 Unidad de Desarrollo Tecnológico UDT, Universidad de Concepción, Coronel 4190000, Chile; \\ p.castano@udt.cl \\ 7 Facultad de Ciencias Forestales, Barrio Universitario s/n, Universidad de Concepción, \\ Concepción 4030000, Chile \\ check for \\ updates \\ Citation: Troncoso-Ortega, E.; \\ 8 Facultad de Ingeniería, Universidad Católica de Temuco, Temuco 4780000, Chile; lschiappacasse@uct.cl \\ * Correspondence: etroncoso@udec.cl
} Castillo, R.d.P.; Reyes-Contreras, P.; Castaño-Rivera, P.; Teixeira Mendonça R.; Schiappacasse, N.; Parra, C. Effects on Lignin Redistribution in Eucalyptus globulus Fibres Pre-Treated by Steam Explosion: A Microscale Study to Cellulose Accessibility. Biomolecules 2021, 11, 507. https://doi.org/ 10.3390/biom11040507

Academic Editor: Jen-Tsung Chen

Received: 5 February 2021

Accepted: 17 March 2021

Published: 29 March 2021

Publisher's Note: MDPI stays neutral with regard to jurisdictional claims in published maps and institutional affiliations.

Copyright: (c) 2021 by the authors. Licensee MDPI, Basel, Switzerland. This article is an open access article distributed under the terms and conditions of the Creative Commons Attribution (CC BY) license (https:// creativecommons.org/licenses/by/ $4.0 /)$.
Abstract: The objective of this study was to investigate structural changes and lignin redistribution in Eucalyptus globulus pre-treated by steam explosion under different degrees of severity $\left(\mathrm{S}_{0}\right)$, in order to evaluate their effect on cellulose accessibility by enzymatic hydrolysis. Approximately $87.7 \%$ to $98.5 \%$ of original glucans were retained in the pre-treated material. Glucose yields after the enzymatic hydrolysis of pre-treated material improved from $19.4 \%$ to $85.1 \%$ when $\mathrm{S}_{0}$ was increased from 8.53 to 10.42. One of the main reasons for the increase in glucose yield was the redistribution of lignin as micro-particles were deposited on the surface and interior of the fibre cell wall. This information was confirmed by laser scanning confocal fluorescence and FT-IR imaging; these microscopic techniques show changes in the physical and chemical characteristics of pre-treated fibres. In addition, the results allowed the construction of an explanatory model for microscale understanding of the enzymatic accessibility mechanism in the pre-treated lignocellulose.

Keywords: steam explosion; Eucalyptus globulus; lignin droplets; enzymatic hydrolysis; FT-IR imaging; chemometric analysis

\section{Introduction}

The recalcitrance of lignocellulosic biomass (LCB) to enzymatic hydrolysis is due to the interaction of the macromolecular components (cellulose, hemicelluloses, and lignin), which generates a rigid, fibrillar structure. For this reason, a pre-treatment process is necessary to break up the lignocellulosic matrix and increase its enzymatic digestibility in order to obtain monosaccharides and oligomers which will generate chemical building blocks or sugar to ferment to second-generation bioethanol [1-3]. Numerous methods have been developed for pre-treating LCB, including biological, physical, chemical, and physicochemical processes. Among the different pre-treatments available, steam explosion (SE) is commonly used for hardwoods, grasses, and agricultural residues [4-7]. SE has several attractive features when compared to other fractionation technologies: lower envi- 
ronmental impact, lower capital investment, higher energy efficiency, no use of hazardous chemicals, and controllable process conditions [2,8-10].

SE pre-treatment combines an autohydrolytic effect with mechanical disorganisation of the lignocellulosic fibre due to the effect of abrupt decompression of the LCB. It promotes breakdown of the lignocellulosic structure, hydrolysis of hemicelluloses, and depolymerisation of the lignin. In the first step, hydrolysis of the hemicelluloses is catalysed by the release of acetic acid from the acetylated xylans, initiated by the formation of hydronium ions generated from water [11,12]. The acid acts as a catalyst of hydrolytic reactions in wood polymers, promoting the solubilisation of hemicelluloses and partial degradation of lignin, and reducing the molar mass of the cellulose [13-15]. This process breaks down the long carbohydrate chains into oligomers and monomeric sugars. Lignin is primarily degraded through haemolytic cleavage of $\beta-\mathrm{O}-4$ ether and other acid-labile linkages, producing a rearrangement of the molecule, and generating new stable carbon-carbon bonds $[16,17]$. These chemical modifications of the fibres have different impacts on cellulose accessibility because lignin and hemicelluloses are important limiting factors for enzyme accessibility and enzymatic hydrolysis. During pre-treatment, the hemicellulose is removed, and the lignin redistributed in large fibre extension; lignin and lignin fragments are rearranged and distributed heterogeneously in the cell wall, where they are deposited on the surface or interior of the fibres. Lignin micro-droplets are formed, produced by the coalescence and migration of lignin and progressive collapse of the microfibrils [18-20]. Other micro-particles deposited on the surface or interior of the fibre, called pseudo-lignin, consist of modified lignin and carbohydrate degradation products [21-23]. Both lignin micro-droplets and pseudo-lignin deposited on the surface or interior of the fibres reduce the efficiency of enzymatic hydrolysis through nonspecific binding of the enzymes, thus creating a physical barrier that blocks enzyme access to the cellulose [23,24].

However, it has also been proposed that the removal of hemicelluloses accompanied by the formation of lignin micro-droplets allows better enzyme action and catalytic adsorption to cellulose. As a result, there would be an increase in conversion rates during enzymatic hydrolysis because these droplets can migrate to certain regions of the cell wall, exposing the cellulose to the enzymes $[19,25]$. To demonstrate this proposal, in this study, Eucalyptus globulus woodchips were pre-treated by SE at different severity conditions. The main goal was to characterise the pre-treated material in order to evaluate, at microscale level, the enzyme accessibility of the pre-treated samples; and at the same time, to evaluate the possible role of the lignin micro-droplets in enzymatic saccharification. Microscopic techniques such as scanning electron microscopy (SEM), laser-scanning confocal fluorescence microscopy (LSCM), and FT-IR imaging were used. A possible action mechanism was proposed based on the results of the experiment.

\section{Materials and Methods}

\subsection{Raw Material}

Woodchips from 10-12-year-old E. globulus trees (donated by CMPC Cellulose S.A., Biobío, Chile) were screened to a size of $2.5 \mathrm{~cm} \times 1.5 \mathrm{~cm} \times 0.3 \mathrm{~cm}$, air-dried to $10 \%$ moisture, and stored under dry conditions until use. The glucan content in the raw material was $45.5 \%$, lignin $23.5 \%$, xylans $15.3 \%$, and acetyls $3.7 \%$ (see Table 1 ).

Additionally, we indicate for the raw material that there were $1.9 \%$ extractives in acetone and $2.0 \%$ ash. Ash content was determined by the TAPPI (Technical Association of Pulp and Paper Industry) method T 211 om-12. 
Table 1. Chemical composition of wood, pulps and liquid fractions obtained from steam explosion pre-treatment at different severities.

\begin{tabular}{|c|c|c|c|c|c|c|}
\hline \multirow[b]{2}{*}{ Sample } & \multirow[b]{2}{*}{$\begin{array}{c}\text { Raw } \\
\text { Material }\end{array}$} & \multicolumn{5}{|c|}{ Pre-Treated Materials } \\
\hline & & 1 & 2 & 3 & 4 & 5 \\
\hline Temperature, ${ }^{\circ} \mathrm{C}$ & - & 180 & 180 & 200 & 220 & 220 \\
\hline Time, $\min$ & - & 9.5 & 36 & 9.5 & 2.0 & 9.5 \\
\hline$S_{0}, \omega=4.6$ & - & 8.5 & 9.1 & 10.4 & 11.6 & 12.3 \\
\hline Solids recovered, $\%$ & & 86.6 & 77.1 & 72.3 & 69.4 & 67.3 \\
\hline Glucans, \% & 45.5 & $44.3 \pm 0.8$ & $44.5 \pm 0.3$ & $43.4 \pm 0.8$ & $42.1 \pm 1.0$ & $41.1 \pm 0.5$ \\
\hline Xylans, \% & 15.3 & $7.1 \pm 0.9$ & $5.9 \pm 0.3$ & $3.4 \pm 0.4$ & $2.0 \pm 0.1$ & $0.3 \pm 0.1$ \\
\hline Lignin, \% & 23.5 & $23.9 \pm 0.4$ & $23.0 \pm 0.1$ & $22.5 \pm 0.8$ & $25.1 \pm 0.4$ & $25.9 \pm 0.1$ \\
\hline \multirow[t]{2}{*}{ Acetyl groups, \% } & 3.6 & nd & nd & nd & nd & nd \\
\hline & & \multicolumn{5}{|c|}{ Liquid phase } \\
\hline Glucans, \% & - & $0.1 \pm 0.0$ & $0.3 \pm 0.0$ & $0.4 \pm 0.0$ & $0.1 \pm 0.0$ & $1.1 \pm 0.0$ \\
\hline Xylans, \% & - & $3.5 \pm 0.1$ & $8.5 \pm 0.1$ & $11.2 \pm 0.2$ & $13.8 \pm 0.2$ & $15.6 \pm 0.1$ \\
\hline Arabinans, $\%$ & - & $0.1 \pm 0.0$ & $0.1 \pm 0.0$ & $0.3 \pm 0.0$ & $0.2 \pm 0.0$ & $0.1 \pm 0.0$ \\
\hline Acetyl groups, \% & & $0.6 \pm 0.0$ & $2.0 \pm 0.1$ & $3.0 \pm 0.0$ & $3.4 \pm 0.1$ & $3.2 \pm 0.1$ \\
\hline Lignin, \% & - & $1.0 \pm 0.1$ & $2.4 \pm 0.3$ & $2.3 \pm 0.3$ & $1.5 \pm 0.2$ & $2.1 \pm 0.1$ \\
\hline Formic acid & - & nd & $0.2 \pm 0.0$ & $0.5 \pm 0.0$ & $0.2 \pm 0.0$ & $0.3 \pm 0.0$ \\
\hline HMF & - & nd & $0.1 \pm 0.0$ & $0.2 \pm 0.0$ & $0.2 \pm 0.0$ & $0.2 \pm 0.0$ \\
\hline Furfural & - & $0.1 \pm 0.0$ & $0.6 \pm 0.0$ & $1.7 \pm 0.1$ & $1.1 \pm 0.1$ & $0.7 \pm 0.0$ \\
\hline
\end{tabular}

$\overline{\mathrm{S}_{0}}$ : severity factor; $\omega$ : empirical parameter related to activation energy and temperature; HMF: 5hydroxymethylfurfural.; nd: not detected; all concentrations are on a dry wood basis.

\subsection{Steam Explosion Process}

SE was carried out in a $5 \mathrm{~L}$ SE reactor (SER) equipped with a $121 \mathrm{~L}$ expansion chamber. In each experiment, the SER was loaded with $200 \mathrm{~g}$ of E. globulus woodchips, dry wood basis (dwb). It was then fed with saturated steam, reaching 180,200 or $220^{\circ} \mathrm{C}$ (equivalent to 146,230 or 348 psig, respectively), for a residence time of $2,9.5$, or $36 \mathrm{~min}$ (Table 1) before being depressurised to atmospheric pressure. The slurry was recovered and filtered, and the liquid was stored at $4{ }^{\circ} \mathrm{C}$ for further analysis of the glucose, xylose, and arabinose concentrations. To calculate the yield of solids (\%), the pre-treated woodchips were airdried for approximately $24 \mathrm{~h}$, after which they were weighed, and the humidity content was determined in a fraction. These two data values were used to calculate the dry mass recovered after pre-treatment.

The severity factor $\left(\mathrm{S}_{0}\right)$, was calculated using the following equation [26]:

$$
\mathrm{S}_{0}=t * \exp \left[\left(T_{\mathrm{H}}-T_{\mathrm{R}}\right) / 4.6\right]
$$

where $t$ is the reaction time in minutes, $T_{\mathrm{H}}$ is the hydrolysis temperature in ${ }^{\circ} \mathrm{C}$, and $T_{\mathrm{R}}$ is a reference temperature of $100{ }^{\circ} \mathrm{C}$. The value of 4.6 represents a constant, $\omega$, which is an empirical parameter related with the activation energy and temperature of the reaction. Using a low value of $\omega(4.6)$ allows better correlation between the severity factor and the enzymatic digestibility of cellulose. In this case, the pre-treatment temperature has a greater influence than time reaction. 


\subsection{Chemical Characterisation of Samples}

The woodchips were milled in a knife mill (Maestranza Proinco S.A., Concepción, Chile) and classified using a set of ASTM sieves (45-60 mesh). Milled wood was extracted with a $90 \%$ acetone solution for $16 \mathrm{~h}$ in Sohxlet apparatus to determine the amount of extractive. Steam-exploded samples were also milled and sieved, but not extracted with acetone. Milled samples were hydrolysed with $72 \%$ sulphuric acid at $30^{\circ} \mathrm{C}$ for $1 \mathrm{~h}(300 \mathrm{mg}$ of sample and $3 \mathrm{~mL}$ of sulphuric acid). The acid was diluted to $4 \%$ by the addition of $84 \mathrm{~mL}$ of water, and the mixture heated at $121^{\circ} \mathrm{C}(1 \mathrm{~atm}$.) for $1 \mathrm{~h}$. The residual material was cooled and filtered through a number 4 porous glass filter. The solids were dried to constant weight at $105^{\circ} \mathrm{C}$ and determined as insoluble lignin. The soluble lignin concentration in the filtrate was determined by measuring the absorbance at $205 \mathrm{~nm}$, using the value of $110 \mathrm{~L} / \mathrm{g}$ $\mathrm{cm}$ as the absorption coefficient. Glucose, xylose, and acetyl groups were determined by HPLC (Merck Hitachi) equipped with a refractive index detector and an Aminex HPX$87 \mathrm{H}$ (Bio-Rad, Hercules, CA, USA) column at $45^{\circ} \mathrm{C}$, eluted at $0.6 \mathrm{~mL} / \mathrm{min}$ with $5 \mathrm{mM}$ $\mathrm{H}_{2} \mathrm{SO}_{4}$ [27]. The factors used to convert sugar monomers to anhydromonomers were 0.90 for glucose (reported as glucan) and 0.88 for xylose (reported as xylans). These factors were calculated based on the water addition to polysaccharides during acid hydrolysis, as the molar mass of each original anhydromonomer in the polysaccharide. Thus, it increased $10 \%$ for glucose (from $162 \mathrm{~g} \mathrm{~mol}^{-1}$ in the anhydromonomer to $180 \mathrm{~g} \mathrm{~mol}^{-1}$ in glucose) and $12 \%$ for xylose (from $132 \mathrm{~g} \mathrm{~mol}^{-1}$ in the anhydromonomer to $150 \mathrm{~g} \mathrm{~mol}^{-1}$ in xylose). Acetyl content was calculated as the acetic acid content multiplied by 0.7 . The percentages of reaction products (glucan, xylan, and lignin) in the solid and liquid fractions were calculated based on the theoretical initial amount of each component loaded into the SER ( $w / w$ dry basis). The moisture content of the solid fraction was determined using a moisture analyser (Sartorius MA35).

\subsection{Scanning Electronic Microscopy (SEM)}

Images were taken of the fibre surfaces before and after pre-treatment using a Jeol JSM-6380LV SEM instrument under a high vacuum, operating with a secondary electron detector. The samples were dried at room temperature and coated with conductive gold paint, particle size $500 \AA$, in a S150 Edwards Sputter Coater. Imaging was performed at a beam-accelerating voltage of $20 \mathrm{kV}$ with a tungsten filament as the electron source.

\subsection{Laser-Scanning Confocal Fluorescence Microscopy (LSCM)}

A LSM710 confocal microscope (Axio Imager.Z1, Jena, Germany) was used with a ZEN 2008, using an excitation laser at Ar 488/ ${ }^{\circ}$ over an emission range of 490-560 nm and a $20 \times$ EC Plan Neofluar objective (N.A. 0.5) zoom 1.7. Software v. 5.0 (Zeiss); multichannel fluorescence images were acquired of the pulps obtained from pre-treatments at the different severities. The pulp samples were suspended in water and two drops of the suspension of each sample were placed on a slide for analysis. The samples were frozen with polyvinyl alcohol (Neg 50 Thermo Scientific) in order to obtain a cross section of the fibres at $10 \mu \mathrm{m}$ on a cryostat Thermo Scientific model Microm HM $525 \mathrm{UV}$ at $-20^{\circ} \mathrm{C}$.

\subsection{FT-IR Microimaging}

FT-IR spectra and images of pulps were analysed by micro-FT-IR using an FT-IR Spectrum Frontier/Spotlight 400 Microscopy System (PerkinElmer, Inc. Waltham, MA, USA) with a linear array of mercury cadmium telluride (MCT) detectors. Areas between $45 \mu \mathrm{m} \times 70 \mu \mathrm{m}$ and $70 \mu \mathrm{m} \times 60 \mu \mathrm{m}$ of isolated fibres previously dried for $8 \mathrm{~h}$ at $45^{\circ} \mathrm{C}$ were scanned by attenuated total reflectance (ATR), using a germanium crystal as the high reflective material, a pixel size of $1.56 \mu \mathrm{m} \times 1.56 \mu \mathrm{m}$, and a spectral range of 1000 to $1800 \mathrm{~cm}^{-1}$ with a spectral resolution of $8 \mathrm{~cm}^{-1}$ and 16 scans per spectrum. The spectra extracted from the images were subjected to ATR correction, removal of atmospheric noise, and baseline correction, and transformed to absorbance before imaging and chemometric analysis. 


\subsection{Chemometric Analysis}

The images were subjected to multivariate analysis by principal component analysis (PCA) to detect the chemical components on the surface of the pre-treated materials. PCA was applied using Spectrum Image software (PerkinElmer Inc.), while the singular value decomposition (SVD) algorithm was performed in MATLAB (Math Works, Inc. Natick, MA, USA). Afterwards, a hypercube with two spatial coordinates related to $x, y$ and a third spectral coordinate was unfolded in a matrix, and mean centring of the data was performed for pre-processing. The interactive method of self-modelling mixture analysis that is called "Pure" was employed for the ALS procedure. This is focused on selecting and using the purest variables as initial estimate values, and concentration as the direction of the variable selection. Non-negativity in spectra, concentrations, and in some cases unimodality, were used as constraints, with 50 iterations and a tolerance criterion for convergence of 0.1 . The pure recovered spectra were then normalised by height.

Theory: A spectroscopic image can be displayed as a data cube with two dimensions related to the $x, y$ coordinates of a scanned surface and a third spectral dimension. However, the measurement variation in an image dataset follows a bilinear model, where the mixed signal recorded in each pixel is described by the concentration-weighted sum of the pure signals of the chemical compounds. As a first step, an unfolding of the original image cube into a matrix of pixel spectra is required. Then, bilinear models can be performed followed by a refolding of the elements according to the original spatial structure of the image. MCRALS is a bilinear method of resolution, based on the mathematical decomposition of a global mixed instrumental response into the pure contributions due to each of the components in the system. One initial estimate, useful for spectroscopic images, is the estimation of purest variables (rows or columns) in the data matrix. This technique marking the most dissimilar row and column profiles in the raw measurements. The purest variables in the concentration direction provide the purest responses in the original measurements, and the purest response variables give the purest concentration profiles. An important consideration in using MCR algorithms is whether or not a unique solution (i.e., a solution with no ambiguity) can be obtained from a given dataset; therefore, some constraints are necessary. For example, the relative concentration and spectral intensity values cannot be negative; therefore, iterations between the MCR algorithms were carried out under non-negative constraints. The application of multivariate curve resolution with alternating least squares (MCR-ALS) for the analysis of FT-IR images is detailed in a previous publication [25].

\subsection{Enzymatic Hydrolysis}

Enzymatic hydrolysis was carried out in $250 \mathrm{~mL}$ Erlenmeyer flasks at $50{ }^{\circ} \mathrm{C}$ in a shaking incubator (Labtech LSI-4018A) at $150 \mathrm{rpm}$ for $72 \mathrm{~h}$. All experiments were run in triplicate with a total volume of $100 \mathrm{~mL}$, composed of $10 \%$ solids $(w / v)$, using a commercial cellulose enzyme complex (NS-22128 CCN3128; $71 \mathrm{FPU} \mathrm{mL}^{-1}$ ) supplemented with $\beta$-glucosidase (NS-22128 DCN00216; $265 \mathrm{CB} \mathrm{mL}^{-1}$ ) and $0.05 \mathrm{M}$ sodium citrate $\mathrm{pH} 4.8$ buffer. The enzyme dosages used were $20 \mathrm{FPU}$ and $20 \mathrm{CBU}$ of cellulase and $\beta$-glucosidase, respectively, per gram of dry material. The content of glucose released during enzymatic treatment was analysed by HPLC [28].

Enzymatic digestibility was measured using the following enzymatic hydrolysis yield:

$$
\text { EH yield }=\frac{\left(\frac{G s}{\text { dry substrate loading }(g)}\right) \times \% S R}{G i} \times 100
$$

where Gs is the amount of glucose released (grams) from the dry substrate loading of pretreated biomass, \%SR is the percentage of solid recovered after the pre-treatment, and $G i$ is the initial amount of glucose in wood expressed as grams of monomer. All measurements were performed in triplicate. 


\section{Results and Discussion}

\subsection{Characterisation of Wood and Pre-Treated Materials}

The chemical characterisations of E. globulus woodchips used for SE pre-treatment and pre-treated materials at different $S_{0}$ conditions are shown in Table 1 . The yield of solids recovered after SE ranged between $67.3 \%$ and $86.6 \%$. The amount of xylans dissolved during the pre-treatment increased with the severity factor due to the solubilisation of hemicelluloses and lignin in accordance with the chemical characterisation of the liquid phase shown in Table 1. The xylan content in the liquid phase increased due to acid hydrolysis that occurs in hydrothermal pre-treatments of hardwoods, where the initial content of acetyls in the raw material acts as a catalyst. The lignin content in the liquid phase varied between $1.0 \%$ and $2.4 \%$, not finding a clear trend between these variations and the severity factor. However, the range of lignin values in the liquid phase was low. The amount of residual xylans obtained in the materials subjected to pre-treatment between $\mathrm{S}_{0} 8.5$ and 12.3 was $7.1 \%$ to $0.3 \%$, approximately $46 \%$ and $1.9 \%$, respectively, of the original amount in the wood. This result agrees with the appearance of the acetyl group in the liquid phase (Table 1) at the same severities. The solubility of xylans depends on the molecular weight and the presence of side chain substituents. Chen et al. (2010) mention that acetyl groups, arabinose, and uronic acid increase the solubility of xylans [29]. Other authors describe SE pre-treatment as an effective method for reducing LCB recalcitrance by removing hemicellulose, disrupting the lignin-hemicellulose matrix, and redistributing lignin in the cell wall layers $[13,28]$, and thus allowing the preservation of glucans under controlled conditions. As the $S_{0}$ of pre-treatment was increased from 8.5 to 12.3, glucan preservation varied between $98.2 \%$ and $90.3 \%$, while lignin content in the same pre-treated materials varied between $22.5 \%$ and $25.9 \%$ (Table 1), slightly higher than the lignin content in the raw material. As mentioned above, the reason for this increase could be the generation of pseudo-lignin during SE pre-treatment. Araya et al. (2015) indicated that the increase in the lignin content of autohydrolysis pre-treated materials at higher severity conditions was partly due to the concomitant loss of polysaccharides and the formation of condensed lignin products. This increase could also be due to the formation of lignin-like compounds from lignin and carbohydrate degradation [21-23].

\subsection{Enzymatic Hydrolysis}

The enzymatic digestibility and glucose yields of materials from E. globulus pre-treated with SE were evaluated, and the results are shown in Figure 1. In general, the efficiency of enzymatic digestibility increased with the $\mathrm{S}_{0}$; for instance, the enzymatic conversion of glucans to glucose increased from $19.4 \%$ to $85.1 \%$ when the $S_{0}$ of the pre-treatment was increased from 8.5 to 10.4. The effect of SE pre-treatment on the glucose yield was attributable to the solubilisation of hemicellulose and the cleavage of lignin-carbohydrate bonds, disrupting the barriers which limit enzymes' access to cellulose [24]. At a severity greater than 11.6, no positive effect was observed on the enzymatic hydrolysis yield; on the contrary, the saccharification yield decreased by more than $10 \%$. This decrease can be attributed to the carbohydrate loss at higher severities. In order to analyse the effect of pre-treatment on the efficiency of enzymatic hydrolysis, we have plotted the glucose release kinetics in terms of the maximum potential glucose that comes from the original biomass, i.e., on a dry wood basis. When considering the yield of solids recovered after pre-treatment, we are considering the loss of glucans which are presented in Table 1, where it is indicated that the raw material contains $45.5 \%$ glucans, and as the severity of the pre-treatment increases, the glucans decrease until reaching $41.1 \%$ at the highest severity $\left(\mathrm{S}_{0}=12.3\right)$. Most of the fermentable sugars present in the pre-treated materials were released in the first $48 \mathrm{~h}$ of enzymatic hydrolysis. 


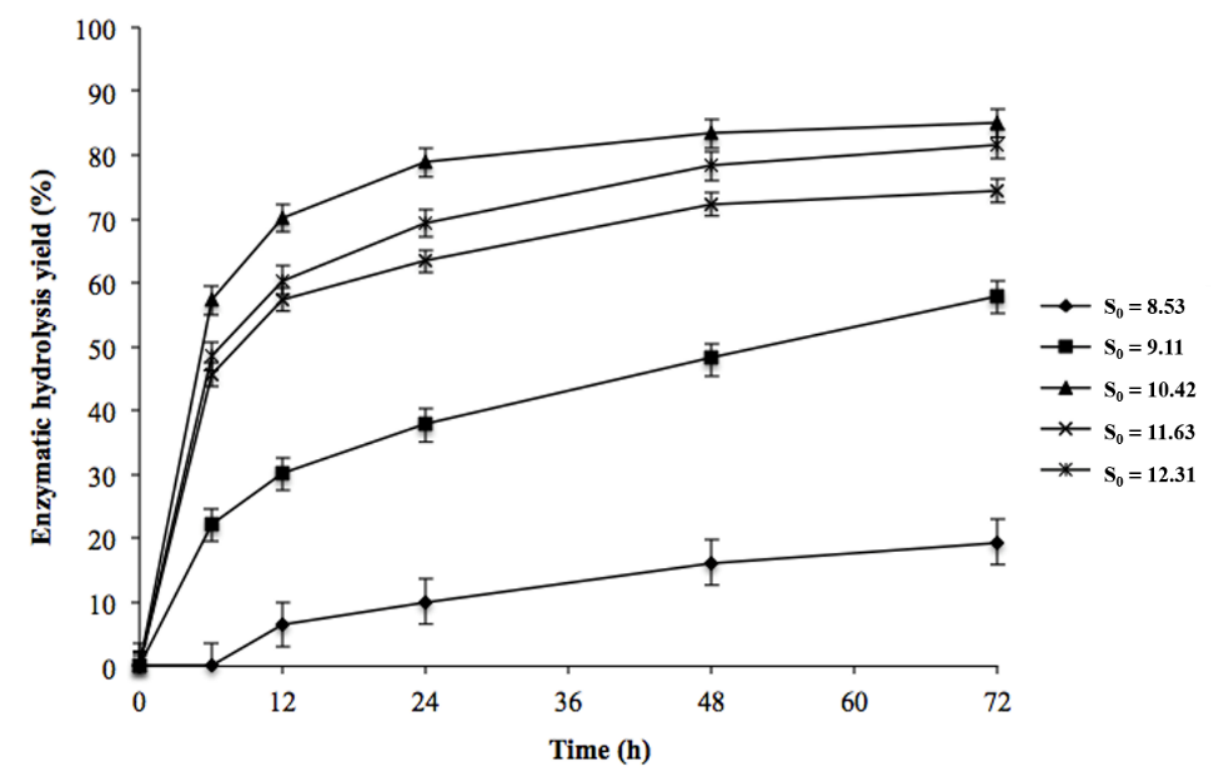

Figure 1. Kinetic profiles of enzymatic hydrolysis of pre-treated solids of E. globulus obtained by steam explosion pre-treatment at different severity factors. The glucans-to-glucose conversion yield is expressed on a dry wood basis. Each sample was performed in triplicate and the error bars correspond to the standard deviation of the repetitions.

\subsection{Microscopic Characterisation of Pre-Treated Material}

To support the above statements on lignin modification and relocation within fibres in the form of droplets, samples were examined by scanning electron microscopy (SEM). The images revealed how the fibrous surface of the pre-treated material changed as the $S_{0}$ of pre-treatments increased from 8.5 to 12.3 (Figure 2).
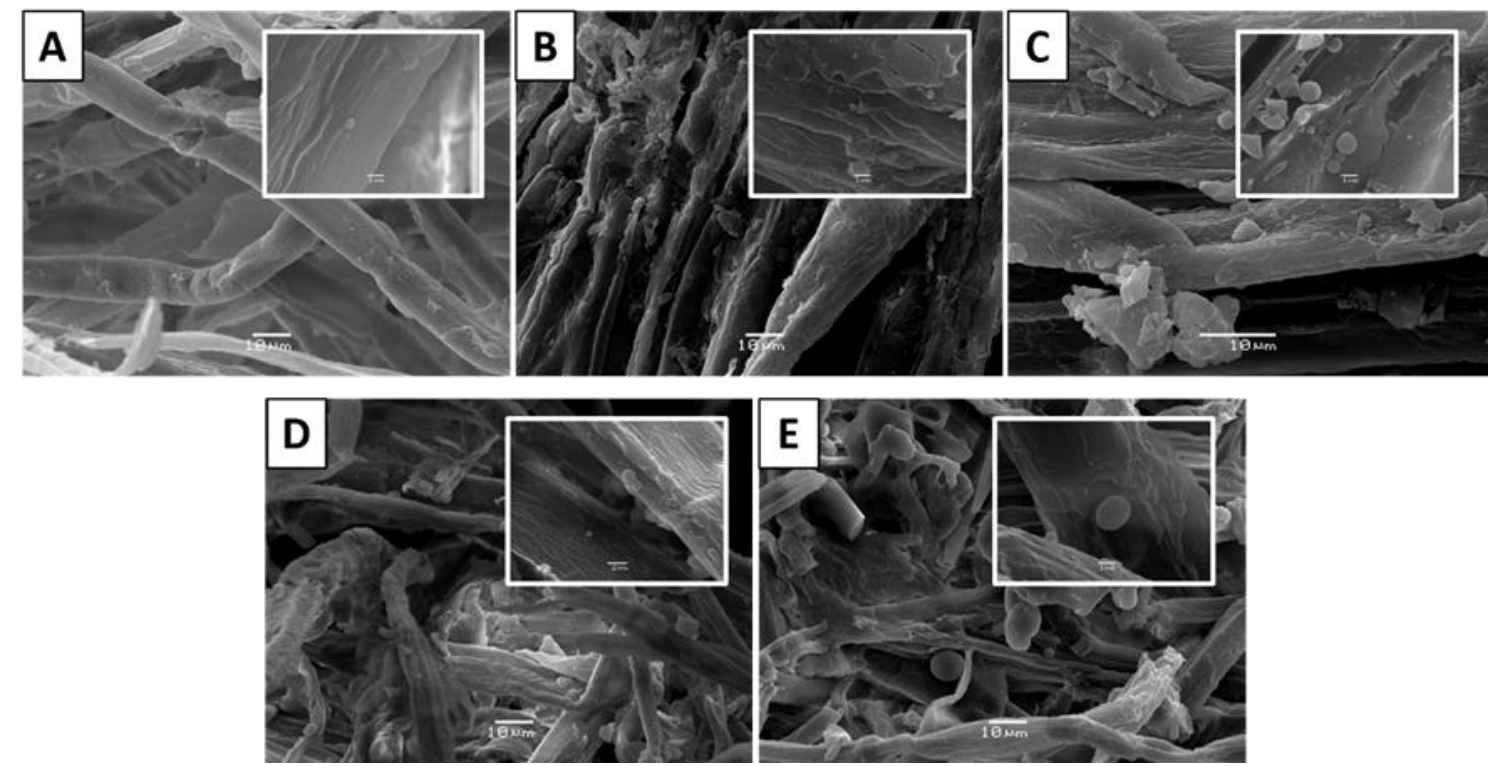

Figure 2. Surface images obtained by scanning electronic microscopy (SEM) of E. globulus pre-treated by steam explosion at different severity factors. (A) $\mathrm{S}_{0}=8.53 ;$ (B) $\mathrm{S}_{0}=9.11$; (C) $\mathrm{S}_{0}=10.42 ;$ (D) $\mathrm{S}_{0}=11.63$; (E) $\mathrm{S}_{0}=12.31$. The insert shows splits, delamination, cracks, and changes in the structure of the fibres and the appearance of lignin droplets. Bar size: $10 \mu \mathrm{m}$; bar size in the inserted micro-image: $1 \mu \mathrm{m}$. 
The sudden depressurisation leads to an "explosion" of the steam inside the lignocellulosic matrix, which promotes the breakdown and defibrillation of its structure, hydrolysis of the hemicellulose, and depolymerisation/repolymerisation of lignin $[28,30]$. As the severity factor of SE pre-treatment increased, the SEM micrographs of the pre-treated material showed that the fibres were deconstructed, forming an amorphous cellulosic material similar to that observed by Gourlay et al., (2012) [31]. For example, fibre obtained at $\mathrm{S}_{0} 8.5$ (Figure 2A) maintained its compact cellular structure, whereas woodchips treated at $\mathrm{S}_{0} 9.1$ (Figure 2B) showed changes in the structure of the fibre with delimitation and mechanical damage. Figure $2 \mathrm{C}$ shows that $\mathrm{SE}$ produced noticeable physical changes in the structure of the fibres obtained at $S_{0} 10.4$, with the presence of micro-particles and micro-droplets between $60 \mathrm{~nm}$ and $1.38 \mu \mathrm{m}$ in diameter (Figure 3). The formation of discrete droplets on the cell wall surface could be caused by the lignin flowing due to the high pre-treatment temperature, and later re-precipitating on the collapsed microfibrils, and by insoluble oligomers generated in acidic conditions that polymerise with degradation products from sugars and lignin. The distribution, size, and abundance of these droplets over the fibre varied, depending on the pre-treatment severity, which is consistent with the observations reported previously by other authors $[19,20,32]$. Woodchips subjected to the highest $S_{0}$, at 11.6 and 12.3 (Figure 2D,E, respectively), suffered the greatest fibre damage, with changes in fibre length, width, or lumen diameter. By correlating the information obtained by SEM, the yields in enzymatic hydrolysis and chemical characterisation, we can show that the degradation of the fibre structure increases when the xylan content in the pre-treated solids decreases. On the other hand, we observed that there was a maximum performance of enzymatic hydrolysis at partial degradations of the fibres produced to severe intermediates.

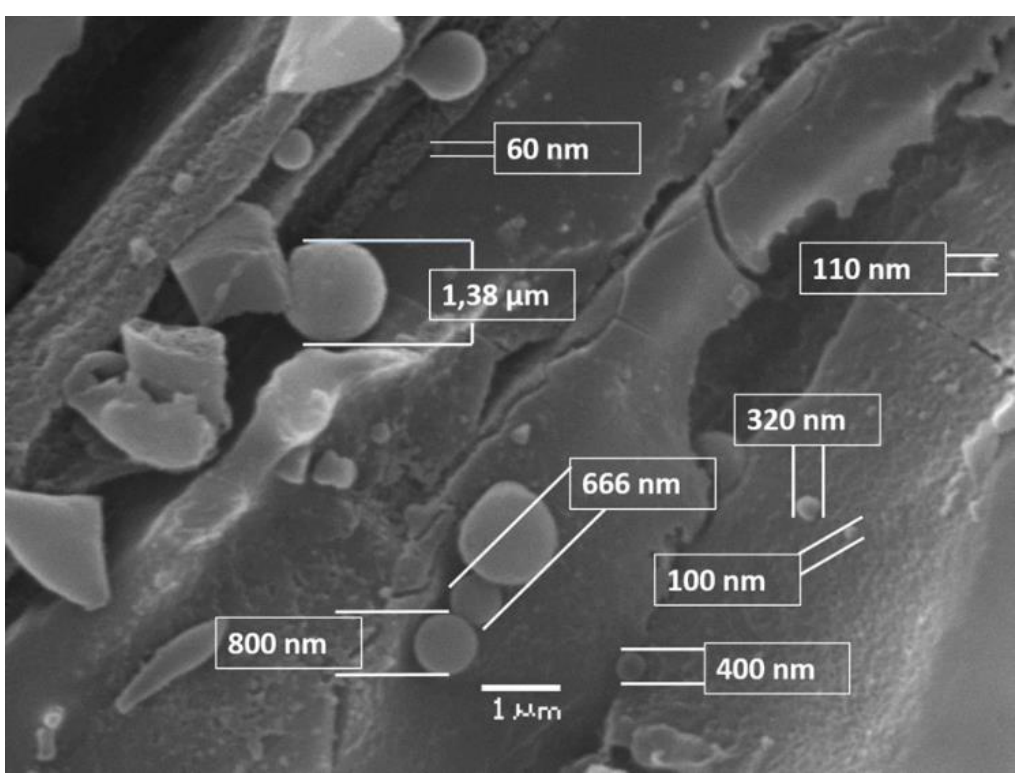

Figure 3. Diameter determination of lignin droplets formed during steam explosion pre-treatment at severity factor $\left(\mathrm{S}_{0}\right)$ of 10.42 using SEM image. The diameters range between $60 \mathrm{~nm}$ and $1380 \mathrm{~nm}$. Bar size: $1 \mu \mathrm{m}$.

The intrinsic autofluorescence of lignin (emission at $530 \mathrm{~nm}$ ) can be used to assess its location on the cell wall using LSCM [19]. The distribution of fluorescence produced by the presence of lignin in materials subjected to different pre-treatments was observed in cross-sections and along the fibres, distributed mainly in the fibre wall. In the cross-section of material pre-treated at $\mathrm{S}_{0} 8.5$, the lignin was observed to be distributed homogeneously in the cell wall and along the fibre, forming a physical barrier that would hinder enzyme access to the cellulose (Figure $4 \mathrm{~A}$ ). When the $\mathrm{S}_{0}$ of the pre-treatment was increased from 8.5 to 9.1, slight delignification of the cell wall (cross-section) was observed, as well as small spheres associated with the condensation of lignin along the fibre (Figure 4B). Figure 4C 
shows a cross section of material pre-treated at $\mathrm{S}_{0} 10.4$; spheres of lignin were deposited in the lumen, which is an important porous structure for the diffusion and subsequent adsorption of enzymes. The close-up image (Figure 5A) shows that some areas of the cell wall have been delignified while others maintain a homogeneous lignin distribution. In Figure 5B, micro and nano drops of lignin can be clearly identified, lodged within the lumen of the cell; this generates areas of the cell wall with lower lignin content (low fluorescence) in which cellulose could be exposed for enzymatic hydrolysis. When the $\mathrm{S}_{0}$ of the pre-treatment was increased to 11.63 (Figure 4D) and 12.31 (Figure 4E), the lignin distribution was extensively modified. It is observed mainly in the cell wall, probably due to the re-condensation of lignin and carbohydrate degradation products. In the crosssection (Figure 4D), physical changes can be observed in the structure of the fibres, while some lignin spheres could be detected in the longitudinal image of the fibre. Figure 4E shows the presence of cracks in the fibre, exposing the internal cell walls, and the loss of cohesion within the fibres is mainly due to the high severity of the pre-treatment.

By LSCM analysis, it was possible to verify a significant redistribution of lignin throughout the cellular structure of the biomass. This is related to the increase in the content of xylans dissolved in the liquid phases obtained from the pre-treatment (Table 1), which would indicate that the action of the pre-treatment, favoured by the presence of acetyl in the medium, helps to dissociate the carbohydrate-lignin complex and, consequently, increases the solubilisation of xylans and the degree of distribution of lignin. It was expected that the enzymatic hydrolysis would improve when the solubilisation of xylans, the heterogeneous redistribution of lignin, and the degradation of the fibre structure increased. However, this is not what happens. It could be that another factor exists, which limits the complete hydrolysis, and it is only possible to reach a maximum glucose and at intermediate severities.
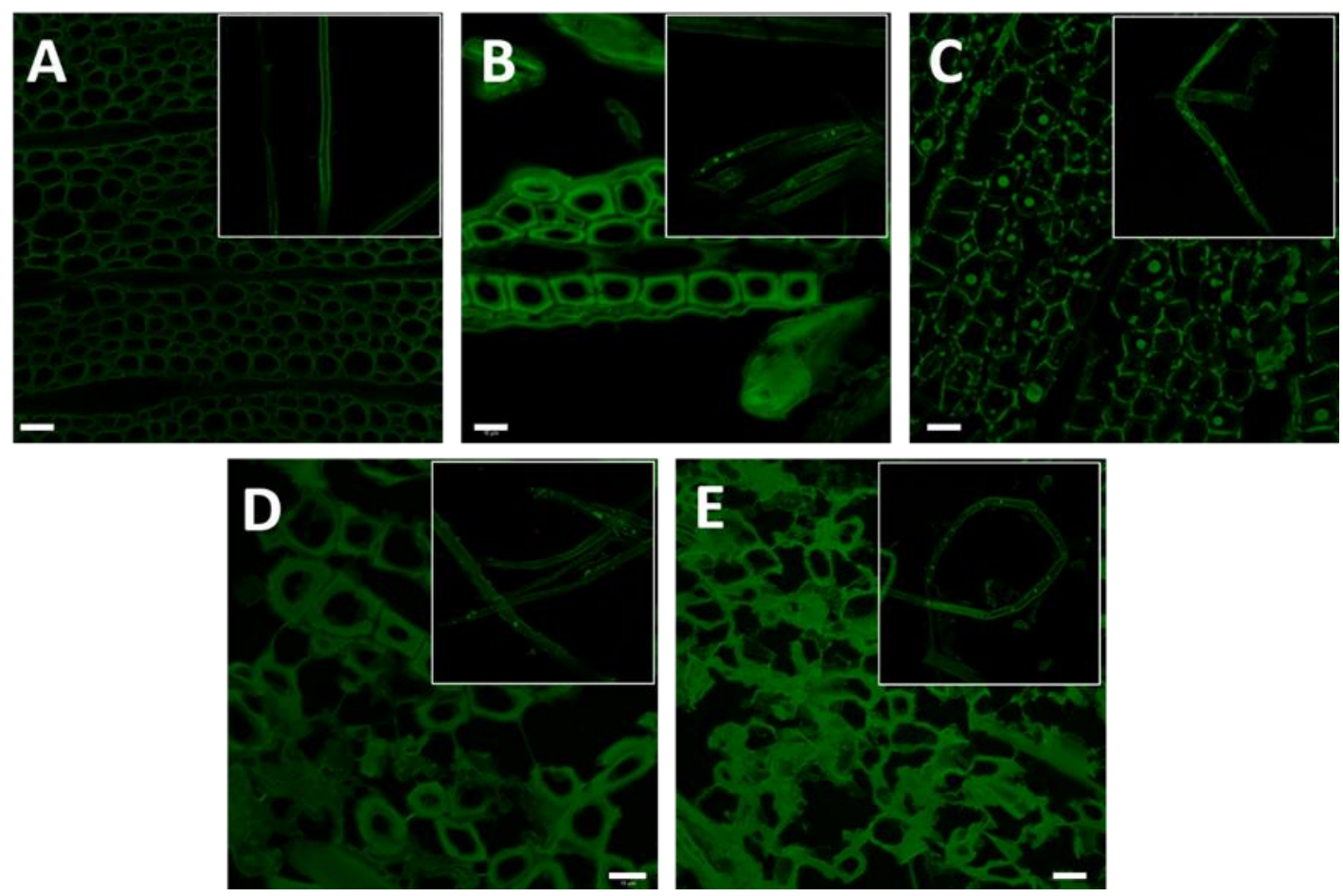

Figure 4. Laser-scanning confocal fluorescence microscopy (LSCM) image of pre-treated materials obtained by steam explosion at different severity factors. (A) $\mathrm{S}_{0}=8.53$; (B) $\mathrm{S}_{0}=9.11 ;$ (C) $\mathrm{S}_{0}=10.42 ;$ (D) $\mathrm{S}_{0}=11.63$; (E) $\mathrm{S}_{0}=12.31$. Bar size: $10 \mu \mathrm{m}$. In the insert, the distribution of lignin along the fibre can be observed. 

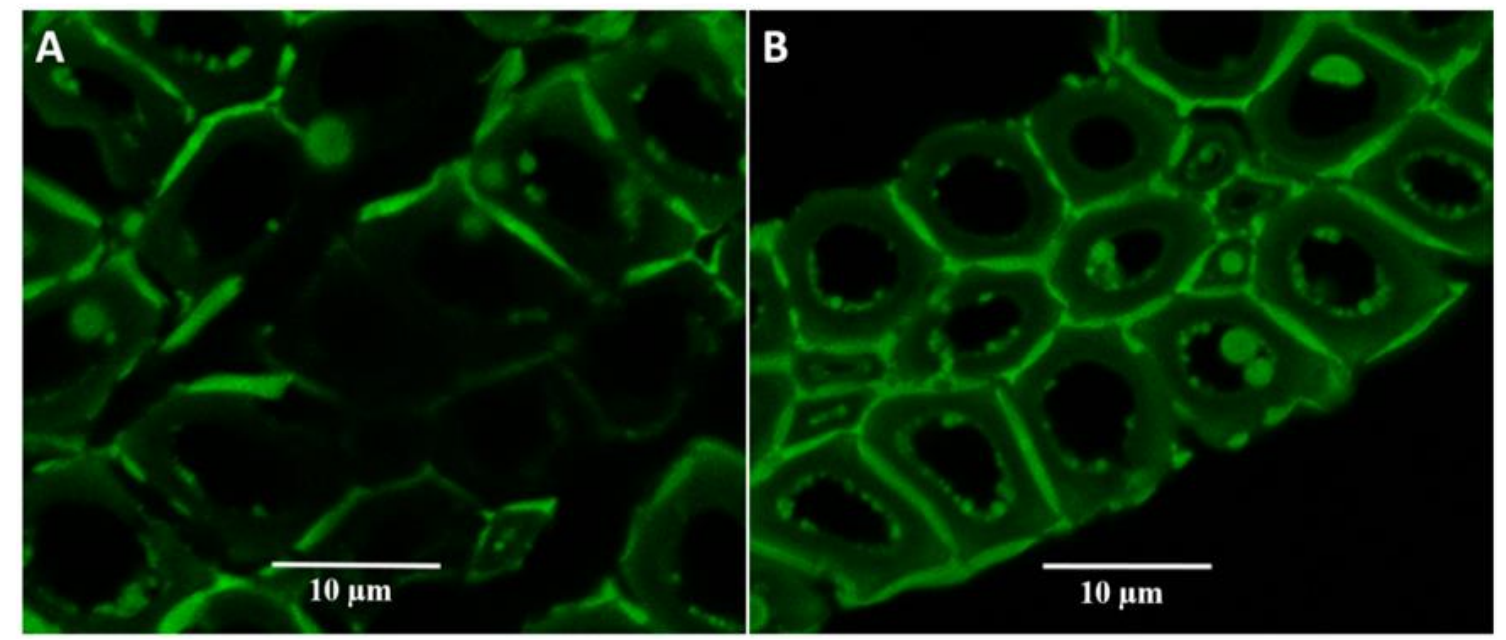

Figure 5. LSCM image. Images of areas with different lignin distributions in pre-treated material at severity $\mathrm{S}_{0} 10.42$.

(A) A zone with highly delignified fibres; and (B) micro and nano drops of lignin lodged inside the cell lumen.

Fourier-transform infrared microspectroscopy was used to obtain chemical information about the surface of the pre-treated fibres, to evaluate the distribution patterns, and generate pure spectra of the lignocellulosic components in the fibres. This technique was supported by multivariate methods including principal component analysis (PCA) and multivariate curve resolution with alternating least squares (MCR-ALS). Samples from three of the five pre-treatments studied were selected, obtained at $\mathrm{S}_{0}$ conditions 8.5, 10.4, and 12.3. Three main components were used for the reconstructions of each sample.

The FT-IR spectra corresponding to three main components in the $S_{0} 8.5$ sample (Figure 6) show an intense band at $1030 \mathrm{~cm}^{-1}$, characteristic of cellulose [33]. The second component is characterised by intense bands at $1420 \mathrm{~cm}^{-1}, 1507 \mathrm{~cm}^{-1}$ and $1596 \mathrm{~cm}^{-1}$, attributable to the aromatic ring in lignin [34]. These bands are also observed with less intensity in components 1 and 3, which indicates that the material has a mixture of lignocellulosic components on its surface, i.e., less chemical deconstruction of the cell wall.

In the pre-treated material obtained at $\mathrm{S}_{0} 10.4$ (Figure 7), an increase is observed in the relative concentration of lignin, shown by the increase in the intensity of the $1510 \mathrm{~cm}^{-1}$ and $1595 \mathrm{~cm}^{-1}$ bands. Components 1 and 3 continue to show an intense band at $1032 \mathrm{~cm}^{-1}$. An increase was also observed in the intensity of the $1327 \mathrm{~cm}^{-1}$ band, especially in the third component, which could mean greater separation of the component on the surface. In addition, in the spectrum of the second component, where the highest intensities of lignin-related bands are detected, an increase was found in the $1323 \mathrm{~cm}^{-1}$ band, indicating that it corresponds to a condensed G-type lignin, substituted in position 5 [35].

In the material pre-treated at the highest severity, significant displacement of the $1505 \mathrm{~cm}^{-1}$ band (observed at $1512 \mathrm{~cm}^{-1}$ ) and the $1595 \mathrm{~cm}^{-1}$ band (observed at $1601 \mathrm{~cm}^{-1}$ ) was identified in the spectrum of the second component (Figure 8). This indicates high chemical modification of lignin, due to the disruption of the propyl group and $\beta-\mathrm{O}-4$ structures by the high severity of pre-treatment [36]. This causes lignin to be affected by condensation reactions to form more stable bonds such as $5-5, \beta-\beta$ or $\beta-5$, which are of the C-C type. In components 1 and 3 , an intense band of cellulose is observed at $1028 \mathrm{~cm}^{-1}$, but in the spectrum of the second component, the intensity of this band decreases significantly, indicating greater deconstruction resulting from the increased severity. This can also be confirmed by the absence of aromatic lignin bands at $1512 \mathrm{~cm}^{-1}$ and $1601 \mathrm{~cm}^{-1}$ in the spectra of components 1 and 3 .

The FT-IR image analysis provided information on the chemical modifications of the biomass components that occurred during pre-treatment. These results could help to respond to the lower enzymatic hydrolysis yields achieved by the materials of higher severity. The greater the severity, the greater the dissociation of biomass constituents 
that was observed, added to a greater degree of condensation of the redistributed lignin. This lignin can act as an inhibitor of cellulases by unproductive adsorption, reducing the catalytic activity of enzymes. This contributes to understanding why the best enzymatic hydrolysis yields are achieved at intermediate severities.
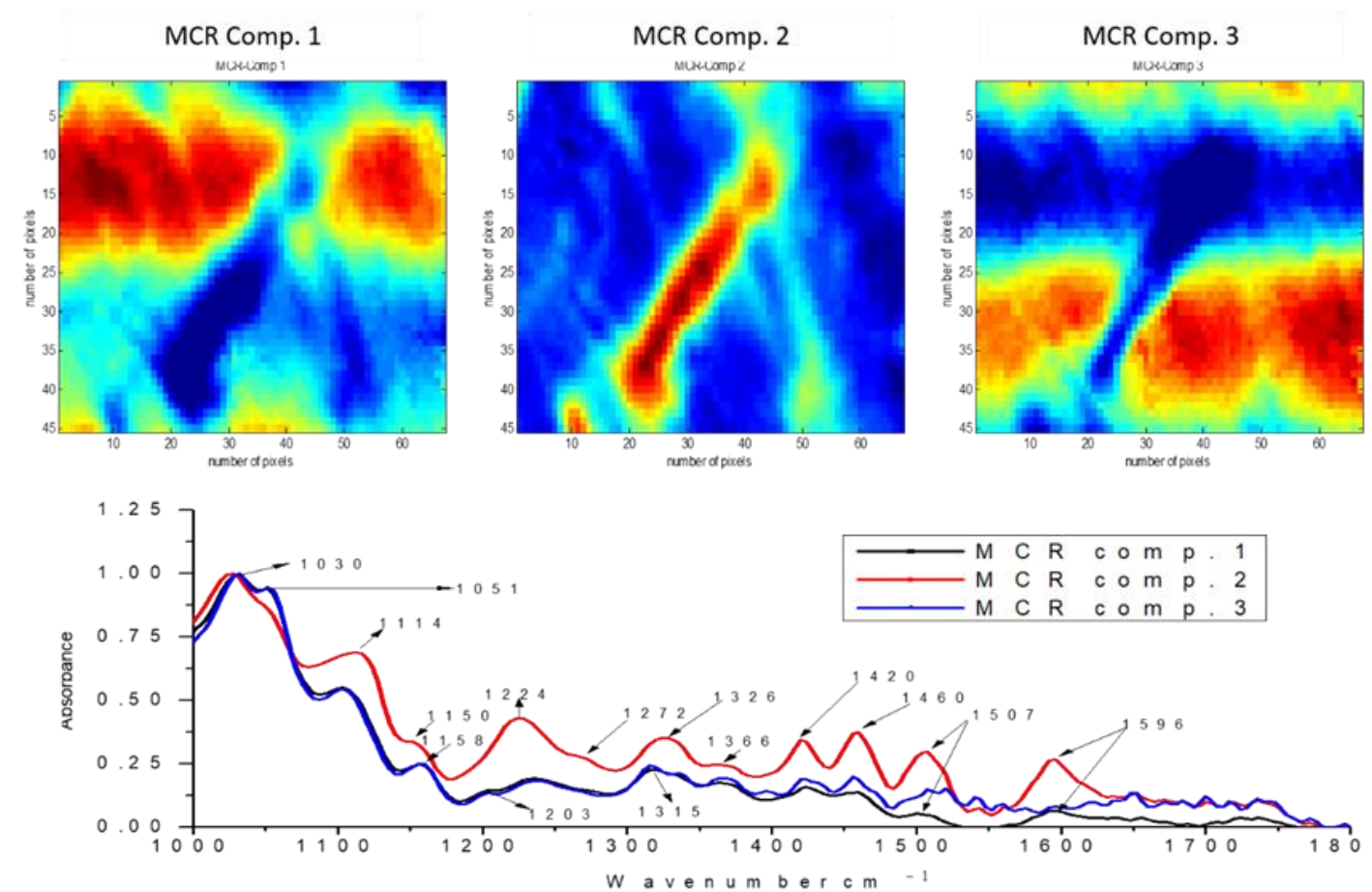

Figure 6. Multivariate curve resolution with alternating least squares (MCR-ALS) relative concentration and recovered spectra of chemical components of pre-treated materials obtained by steam explosion. FT-IR micro-image of E. globulus pre-treated at severity $\mathrm{S}_{0} 8.53$.
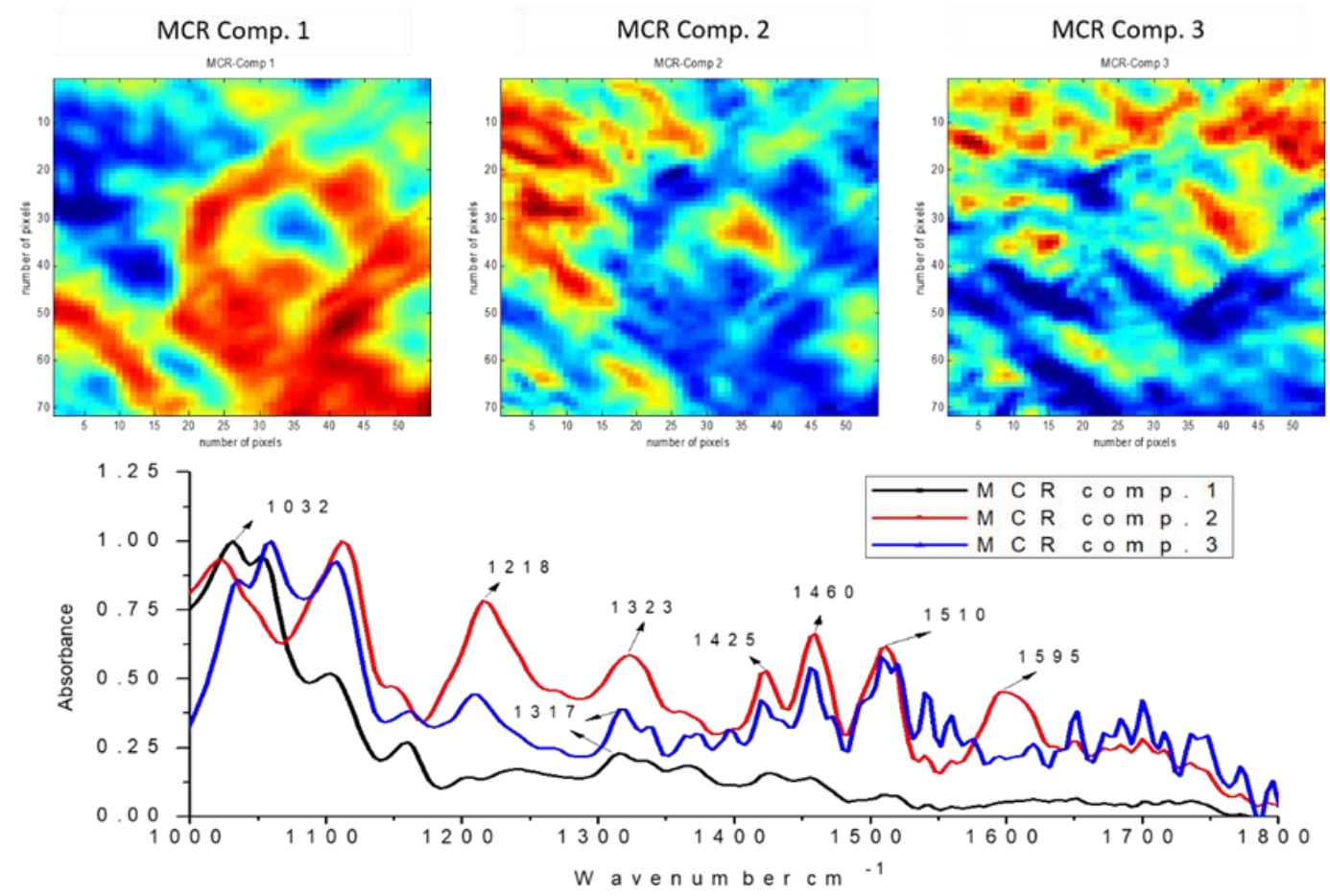

Figure 7. MCR-ALS relative concentration and recovered spectra of chemical components of pre-treated materials obtained by steam explosion. FT-IR micro-image of E. globulus pre-treated at severity $\mathrm{S}_{0} 10.42$. 


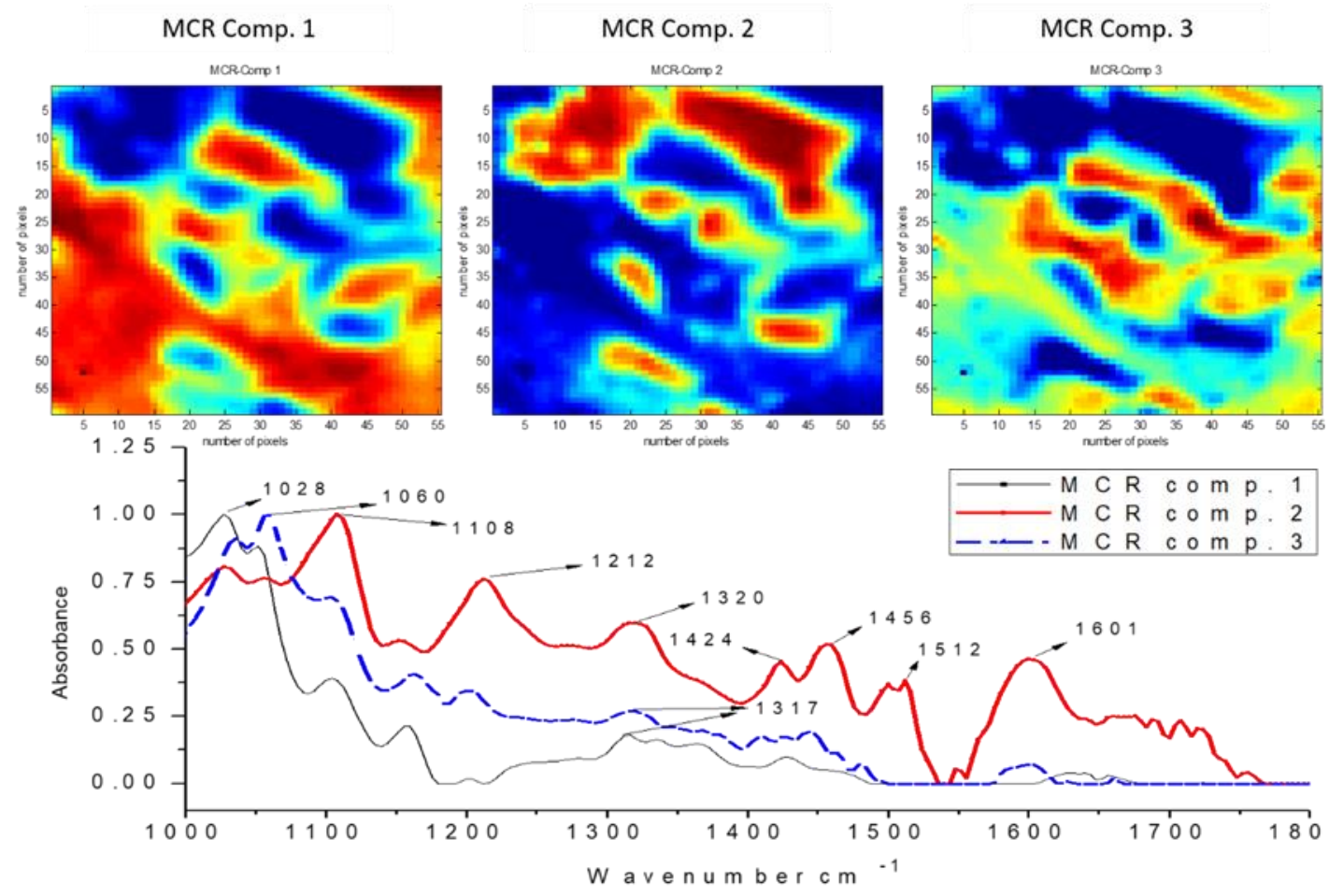

Figure 8. MCR-ALS relative concentration and recovered spectra of chemical components of pre-treated materials obtained by steam explosion. FT-IR micro-image of E. globulus pre-treated at severity $\mathrm{S}_{0} 12.31$.

\subsection{Study of Micro-Accessibility of E. globulus Pre-Treated by Steam Explosion}

The enzymatic hydrolysis yield is influenced by physicochemical and structural changes in the pre-treated material. A significant removal of hemicellulose in the biomass was determined, promoting both the degradation of the fibre structures and the redistribution of lignin. We can observe by SEM analysis that as the severity of the steam explosion increases, the degree of degradation of the fibres increases, probably related to the decrease in xylans in the pre-treated materials. By LSCM analysis, it was possible to verify a significant redistribution of lignin throughout the cellular structure of the biomass. This is related to the increase in the content of xylans dissolved in the liquid phases obtained from the pre-treatment (Table 1), which would indicate that the action of the pre-treatment, favoured by the presence of acetyl in the medium, helps to dissociate the carbohydrate-lignin complex, and, consequently, increasing the solubilisation of xylans and increasing the degree of distribution of lignin. To represent this phenomenon, Figure 9 shows a hypothetical model of the micro-accessibility mechanism proposed to explain the changes inside the fibres, where the effect of SE pre-treatment on the heterogeneous distribution of lignin after pre-treatment is shown. When hemicelluloses are removed, lignin is more exposed to changes that promote its redistribution in the form of micro-droplets; these are randomly relocated in different regions of the fibre surface or inside the cell wall, leaving the cellulose more exposed to enzymes. At low temperature, the lignin is insoluble in water due to the high dielectric constant of water $\left(78.5\right.$ at $\left.25^{\circ} \mathrm{C}\right)$; however, at the extreme conditions of temperature and pressure used in the pre-treatments, the dielectric constant of water decreases dramatically [37], generating a favourable environmental for the solubilisation of lignin. Subsequently, during the cooling process, the dielectric constant of water is restored, causing the precipitation and formation of lignin micro-droplets on the fibres [32]. 


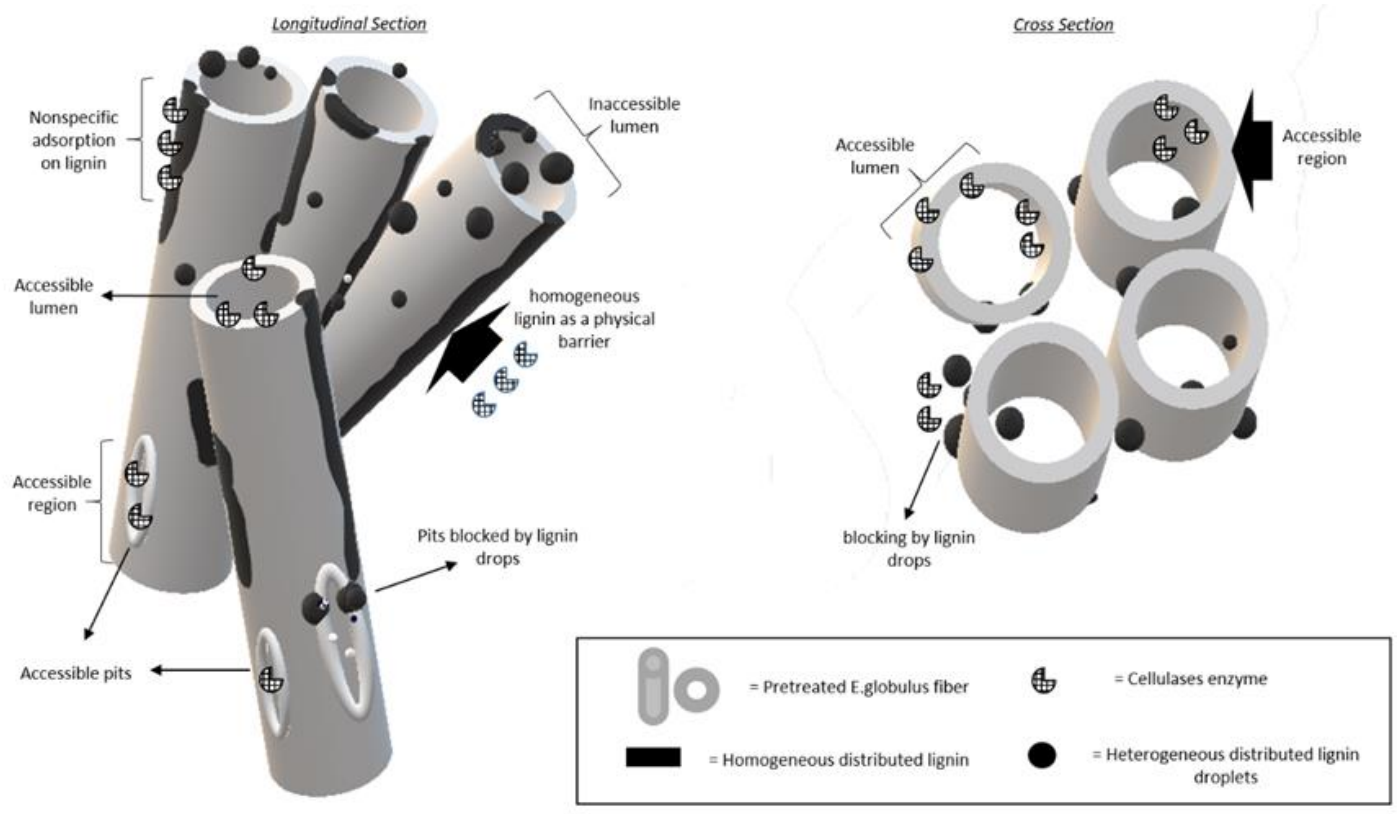

Figure 9. Hypothetical diagrammatic presentation of the effect of pre-treatment on the formation of micro and nano lignin droplets generating a heterogeneous distribution of lignin, increasing the areas of enzymatic microaccessibility and subsequent digestion of cellulose. Pre-treated fibres are represented lengthwise on the left and in cross section on the right. $\mathrm{S}_{0} 8.53$.

\section{Conclusions}

This work demonstrates that the severity conditions employed during the SE pretreatment of E. globulus influenced the enzymatic hydrolysis of the pre-treated material cellulose. The microscopy analysis showed that a relationship exists between the SE pretreatment severity conditions and the degradation degree of the fibre structures, the heterogeneous redistribution of lignin, and the chemical changes of redistributed lignin. With respect to lignin redistribution, it was observed on the surface and the interior of the E. globulus fibre, in the form of micro and nanodroplets, and hence the cellulose of the fibre was more exposed. Moreover, with respect to the chemical changes of redistributed lignin, it presented a higher degree of condensation as severity increased.

These physical-chemical effects were correlated with a greater solubilisation of xylans from biomass to the liquid phase, due to the action of acetyl groups of the raw material. The solubilisation of the xylans could be the main phenomenon that leads to the dissociation of the carbohydrate-lignin complex, promoting the degradation of the fibre structure and the redistribution of lignin. The migration and redistribution of lignin in the residual biomass significantly improved enzymatic hydrolysis.

On the other hand, it was determined that the maximum conversion to glucose was achieved at conditions of intermediate severity. At higher severity conditions, the condensation of lignin increased, which caused an unproductive adsorption of the enzymes on it. Based on the experimental evidence found, a model was proposed that explains the effect of pre-treatment with SE in lignocellulosic material fibre and its impact on enzymatic hydrolysis.

Author Contributions: Conceptualization, C.P. and E.T.-O.; methodology, E.T.-O., R.d.P.C.; data analysis and interpretation of results, E.T.-O., R.d.P.C., P.R.-C. and P.C.-R.; resources, C.P. and N.S.; writing—original draft preparation, E.T.-O., C.P., P.R.-C.; R.d.P.C., P.C.-R. and R.T.M.; writing—review and editing, E.T.-O., C.P., N.S. and R.T.M.; supervision, C.P., N.S. and R.T.M.; project administration, C.P. and E.T.-O.; funding acquisition, C.P., R.d.P.C., N.S. and P.R.-C. All authors have read and agreed to the published version of the manuscript. 
Funding: This research was funded by Innova Chile CORFO grant 208-7302 and Fondecyt Regular 1191281 (ANID, Chile). Pablo Reyes-Contreras was support by an Innovation Fund for Competitiveness of the Chilean Economic Development Agency 555 (CORFO) under Grant No. 13CEI2-21839. Eduardo Troncoso-Ortega thanks the ANID/2020-21202445 National Doctoral Scholarship.

Institutional Review Board Statement: Not applicable.

Informed Consent Statement: Not applicable.

Data Availability Statement: Not applicable.

Acknowledgments: The authors are grateful to "Centro de Microscopia Avanzada CMA Bío Bío" of University of Concepción, ANID—Millennium Science Initiative Program-NCN17_040. We also thank German Osorio and Joanna Tereszczuk for help in microscopy, and Marco Sierra Ortega for help in graphic design. This work is dedicated to Juanita Freer Calderón, leader of our research group, for all these years of great dedication to the research and formation of numerous researchers in the lignocellulosic biomass field.

Conflicts of Interest: The authors declare no conflict of interest.

\section{References}

1. Nielsen, F.; Galbe, M.; Zacchi, G.; Wallberg, O. The effect of mixed agricultural feedstocks on steam pretreatment, enzymatic hydrolysis, and cofermentation in the lignocellulose-to-ethanol process. Biomass Convers. Biorefinery 2019. [CrossRef]

2. Jacquet, N.; Haubruge, E.; Richel, A. Production of biofuels and biomolecules in the framework of circular economy: A regional case study. Waste Manag. Res. 2015, 33, 1121-1126. [CrossRef] [PubMed]

3. Matsakas, L.; Raghavendran, V.; Yakimenko, O.; Persson, G.; Olsson, E.; Rova, U.; Olsson, L.; Christakopoulos, P. Lignin-first biomass fractionation using a hybrid organosolv-Steam explosion pretreatment technology improves the saccharification and fermentability of spruce biomass. Bioresour. Technol. 2019, 521-528. [CrossRef] [PubMed]

4. Montipó, S.; Ballesteros, I.; Martins, A.F.; Ballesteros, M.; Camassola, M. Optimisation of uncatalysed steam explosion of lignocellulosic biomasses to obtain both C6- and C5-sugars. Waste Biomass Valorization 2018, 11, 1-14. [CrossRef]

5. Liu, Z.H.; Qin, L.; Pang, F.; Jin, M.J.; Li, B.Z.; Kang, Y.; Dale, B.E.; Yuan, Y.J. Effects of biomass particle size on steam explosion pretreatment performance for improving the enzyme digestibility of corn stover. Ind. Crops Prod. 2013, 44, 176-184. [CrossRef]

6. Sui, W.; Chen, H. Study on loading coefficient in steam explosion process of corn stalk. Bioresour. Technol. 2015, 179, 534-542. [CrossRef]

7. Walker, D.J.; Gallagher, J.; Winters, A.; Somani, A.; Ravella, S.R.; Bryant, D.N. Process optimization of steam explosion parameters on multiple lignocellulosic biomass using taguchi method-A critical appraisal. Front. Energy Res. 2018, 6, 1-13. [CrossRef]

8. Reinerte, S.; Andzs, M.; Tupciauskas, R.; Veveris, A.; Gravitis, J. Steam explosion as a pre-treatment method for bio-refined hybrid aspen lignocellulose. Environ. Technol. Resour. Proc. Int. Sci. Pract. Conf. 2017, 3, 276. [CrossRef]

9. Rodríguez, F.; Sanchez, A.; Parra, C. Role of steam explosion on enzymatic digestibility, xylan extraction, and lignin release of lignocellulosic biomass. ACS Sustain. Chem. Eng. 2017, 5, 5234-5240. [CrossRef]

10. Vargas, R.; Vecchietti, A. Modeling the thermochemical pretreatment of eucalyptus globulus for bioethanol production. Ind. Eng. Chem. Res. 2018, 57, 12458-12467. [CrossRef]

11. Castro, J.F.; Parra, C.; Yáñez-S, M.; Rojas, J.; Teixeira Mendoncìa, R.; Baeza, J.; Freer, J. Optimal pretreatment of eucalyptus globulus by hydrothermolysis and alkaline extraction for microbial production of ethanol and xylitol. Ind. Eng. Chem. Res. 2013, 52, 5713-5720. [CrossRef]

12. Marzialetti, T.; Salazar, J.P.; Ocampos, C.; Chandra, R.; Chung, P.; Saddler, J.; Parra, C. Second-generation ethanol in chile: Optimisation of the autohydrolysis of eucalyptus globulus. Biomass Convers. Biorefinery 2014, 4, 125-135. [CrossRef]

13. Leschinsky, M.; Sixta, H.; Patt, R. Detailed mass balances of the autohydrolysis of eucalyptus globulus at $170{ }^{\circ} \mathrm{C}$. Biouresources 2009, 4, 687-703.

14. Ramos, L.P.; Breuil, C.; Saddler, J.N.; Kushner, D.J. Steam pretreatment conditions for effective enzymatic hydrolysis and recovery yields of eucalyptus viminalis wood chips. Holzforschung 1992, 46, 149-154. [CrossRef]

15. Martín-Sampedro, R.; Eugenio, M.E.; García, J.C.; Lopez, F.; Villar, J.C.; Diaz, M.J. Steam explosion and enzymatic pre-treatments as an approach to improve the enzymatic hydrolysis of eucalyptus globulus. Biomass Bioenergy 2012, 42, 97-106. [CrossRef]

16. Ramos, L.P. The chemistry involved in the steam treatment of lignocellulosic materials. Quim. Nova 2003, 26, 863-871. [CrossRef]

17. Auxenfans, T.; Crônier, D.; Chabbert, B.; Paës, G. Understanding the Structural and Chemical Changes of Plant Biomass Following Steam Explosion Pretreatment. Biotechnol. Biofuels 2017, 10, 1-17. [CrossRef] [PubMed]

18. Donohoe, B.S.; Decker, S.R.; Tucker, M.P.; Himmel, M.E.; Vinzant, T.B. Visualizing lignin coalescence and migration through maize cell walls following thermochemical pretreatment. Biotechnol. Bioeng. 2008, 101, 913-925. [CrossRef]

19. Araya, F.; Troncoso, E.; Mendonça, R.T.; Freer, J. Condensed lignin structures and re-localization achieved at high severities in autohydrolysis of eucalyptus globulus wood and their relationship with cellulose accessibility. Biotechnol. Bioeng. 2015, 112, 1783-1791. [CrossRef] 
20. Arévalo, C.; Freer, J.; Naulin, P.A.; Barrera, N.P.; Troncoso, E.; Araya, J.; Peña-Farfal, C.; Castillo, R.P. Study of the ultrastructure of eucalyptus globulus wood substrates subjected to auto-hydrolysis and diluted acid hydrolysis pre-treatments and its influence on enzymatic hydrolysis. Bioenergy Res. 2017, 10, 714-727. [CrossRef]

21. Sannigrahi, P.; Kim, D.H.; Jung, S.; Ragauskas, A. Pseudo-lignin and pretreatment chemistry. Energy Environ. Sci. 2011, 4, 1306-1310. [CrossRef]

22. Kumar, R.; Hu, F.; Sannigrahi, P.; Jung, S.; Ragauskas, A.J.; Wyman, C.E. Carbohydrate derived-pseudo-lignin can retard cellulose biological conversion. Biotechnol. Bioeng. 2013, 110, 737-753. [CrossRef]

23. Hu, F.; Jung, S.; Ragauskas, A. Pseudo-lignin formation and its impact on enzymatic hydrolysis. Bioresour. Technol. 2012, 117, 7-12. [CrossRef] [PubMed]

24. Li, H.; Pu, Y.; Kumar, R.; Ragauskas, A.J.; Wyman, C.E. Investigation of lignin deposition on cellulose during hydrothermal pretreatment, its effect on cellulose hydrolysis, and underlying mechanisms. Biotechnol. Bioeng. 2014, 111, 485-492. [CrossRef] [PubMed]

25. Castillo, R.P.; Araya, J.; Troncoso, E.; Vinet, S.; Freer, J. Fourier transform infrared imaging and microscopy studies of pinus radiata pulps regarding the simultaneous saccharification and fermentation process. Anal. Chim. Acta 2015, 866, 10-20. [CrossRef]

26. Kim, Y.; Kreke, T.; Mosier, N.S.; Ladisch, M.R. Severity factor coefficients for subcritical liquid hot water pretreatment of hardwood chips. Biotechnol. Bioeng. 2014, 111, 254-263. [CrossRef]

27. Mendonça, R.T.; Jara, J.F.; González, V.; Elissetche, J.P.; Freer, J. Evaluation of the white-rot fungi ganoderma australe and ceriporiopsis subvermispora in biotechnological applications. J. Ind. Microbiol. Biotechnol. 2008, 35, 1323-1330. [CrossRef]

28. Reyes, P.; Márquez, N.; Troncoso, E.; Parra, C.; Teixeira Mendonça, R.; Rodríguez, J. Evaluation of combined dilute acid-kraft and steam explosion-kraft processes as pretreatment for enzymatic hydrolysis of pinus radiata wood chips. BioResources 2015, 11, 612-625. [CrossRef]

29. Chen, X.; Lawoko, M.; Heiningen, A. Van kinetics and mechanism of autohydrolysis of hardwoods. Bioresour. Technol. 2010, 101, 7812-7819. [CrossRef]

30. Ruiz, E.; Cara, C.; Manzanares, P.; Ballesteros, M.; Castro, E. Evaluation of steam explosion pre-treatment for enzymatic hydrolysis of sunflower stalks. Enzym. Microb. Technol. 2008, 42, 160-166. [CrossRef]

31. Gourlay, K.; Arantes, V.; Saddler, J.N. Use of substructure-specific carbohydrate binding modules to track changes in cellulose accessibility and surface morphology during the amorphogenesis step of enzymatic hydrolysis. Biotechnol. Biofuels 2012, 5, 1-14. [CrossRef]

32. Troncoso, E.; Castillo, R.; Valenzuela, R.; Reyes, P.; Freer, J.; Norambuena, M.; Rodríguez, J.; Parra, C. Chemical and microstructural changes in eucalyptus globulus fibers subjected to four different pretreatments and their influence on the enzymatic hydrolysis. J. Chil. Chem. Soc. 2017, 62, 3442-3446. [CrossRef]

33. Popescu, C.M.; Larsson, P.T.; Olaru, N.; Vasile, C. Spectroscopic study of acetylated kraft pulp fibers. Carbohydr. Polym. 2012, 88, 530-536. [CrossRef]

34. Pandey, K.K.; Pitman, A.J. FTIR studies of the changes in wood chemistry following decay by brown-rot and white-rot fungi. Int. Biodeterior. Biodegrad. 2003, 52, 151-160. [CrossRef]

35. Faix, O. Classification of lignins from different botanical origins by FT-IR spectroscopy. Holzforschung 1991, 45, 21-28. [CrossRef]

36. Kumar, R.; Mago, G.; Balan, V.; Wyman, C.E. Physical and chemical characterizations of corn stover and poplar solids resulting from leading pretreatment technologies. Bioresour. Technol. 2009, 100, 3948-3962. [CrossRef]

37. Uematsu, M.; Frank, E.U. Static dielectric constant of water and steam. J. Phys. Chem. Ref. Data 1980, 9, 1291-1306. [CrossRef] 